\title{
Synoptic Characteristics of 14-Day Extreme Precipitation Events across the United States
}

\author{
GREGORY C. JENNRICH AND JASON C. FURTADO \\ School of Meteorology, University of Oklahoma, Norman, Oklahoma \\ JEFFREY B. BASARA \\ School of Meteorology, and Civil and Environmental Engineering, University of Oklahoma, Norman, Oklahoma \\ ELINOR R. MARTIN \\ School of Meteorology, University of Oklahoma, and South Central Climate Adaptation Science Center, Norman, Oklahoma
}

(Manuscript received 24 July 2019, in final form 25 April 2020)

\begin{abstract}
Although significant improvements have been made to the prediction and understanding of extreme precipitation events in recent decades, there is still much to learn about these impactful events on the subseasonal time scale. This study focuses on identifying synoptic patterns and precursors ahead of an extreme precipitation event over the contiguous United States (CONUS). First, we provide a robust definition for 14-day "extreme precipitation events" and partition the CONUS into six different geographic regions to compare and contrast the synoptic patterns associated with events in those regions. Then, several atmospheric variables from ERA-Interim (e.g., geopotential height and zonal winds) are composited to understand the evolution of the atmospheric state before and during a 14-day extreme precipitation event. Common synoptic signals seen during events include significant zonally oriented trough-ridge patterns, an energized subtropical jet stream, and enhanced moisture transport into the affected area. Also, atmospheric-river activity increases in the specific region during these events. Modes of climate variability and lagged composites are then investigated for their potential use in lead-time prediction. Key findings include synoptic-scale anomalies in the North Pacific Ocean and regional connections to modes such as the Pacific-North American pattern and the North Pacific Oscillation. Taken together, our results represent a significant step forward in understanding the evolution of 14-day extreme precipitation events for potential damage and casualty mitigation.
\end{abstract}

\section{Introduction}

Extreme precipitation events are among the most devastating natural hazards in the contiguous United States (CONUS). These events pose significant risks and far-reaching impacts to life, property, and the economy. From 1980 to 2018, the top 30 U.S. inland flooding events cost a combined $\$ 124$ billion and resulted in over 500 fatalities (National Centers for Environmental Information 2019). Although flooding can arise from many sources (e.g., rapid snowpack melt, overflowing rivers/lakes, storm surge), heavy precipitation is a significant contributor. As such, improved understanding and prediction of extreme precipitation events would help to reduce these socioeconomic losses. The meteorology

\footnotetext{
Corresponding author: Gregory C. Jennrich, gregory.c.jennrich1@ou.edu
}

community, among others, particularly struggles with improving the prediction of extreme weather events (including hazards other than heavy precipitation like heat waves, drought, and cold air outbreaks) on the subseasonal-toseasonal (S2S) time scale (i.e., the period roughly spanning two weeks to three months) (Brunet et al. 2010; National Academies of Sciences, Engineering and Medicine 2016). While extreme events on any scale can have significant impacts, events longer than two weeks have more widespread losses due to the duration and the potential regional or larger scale of the events.

There are many occurrences of longer-term extreme events accompanied with major socioeconomic impacts. The historic 1993 Mississippi River basin flood is an example of an extreme precipitation event that occurs over several months. This single event cost billions of dollars in damage and was forced, in part, by persistent atmospheric patterns favoring frequent heavy precipitation 
episodes across the central United States (e.g., Kunkel et al. 1994). In addition, a mid-Atlantic extreme precipitation event during June/July of 2006 was also high impact, with widespread losses in life and property due to severe flooding resulting from the rainfall. A combination of anomalous transport of moist tropical air and a blocking ridge lead to this extended period of rainfall (e.g., Gitro et al. 2014). More recently, a series of short-wave troughs and anomalous moisture resulting in heavy rainfall over Oklahoma and Texas during May and June of 2015 led to widespread flooding and extensive damage (e.g., Wang et al. 2015). Records for monthly precipitation totals were shattered across Oklahoma and parts of Texas, including for Oklahoma City [19.48 in. $(49.48 \mathrm{~cm})]$ and the Oklahoma statewide average $[14.40$ in. $(36.58 \mathrm{~cm})]$ (Oklahoma Mesonet 2015). A more complete understanding of these events may help forecasters predict them and public officials prepare for the multiple impacts of these prolonged heavy rainfall episodes.

Past studies on extreme precipitation events have examined long-term precipitation trends, specific case studies of extreme events, and characteristics of daily precipitation extremes, often in a specific locale. Several studies (e.g., Karl and Knight 1998; Mallakpour and Villarini 2016; Armal et al. 2018) have indicated that the frequency of daily extreme precipitation and annual totals have increased across several regions of the United States over the last half century, particularly in areas east of the Rocky Mountains. Armal et al. (2018) found that $59.6 \%$ of the stations sampled featured no long-term $(\sim 100 \mathrm{yr})$ trend in precipitation. For the stations with trends, well over half could be attributed to anthropogenic forcing. An increase in CONUS precipitation may be in part attributed to increases in $\geq 90$ thpercentile precipitation events (Karl and Knight 1998). In terms of extreme precipitation, Mallakpour and Villarini (2016) suggested the frequency, not magnitude, of heavy precipitation is increasing over large areas of the CONUS, with the exception of the northwestern United States and Northern California. In regional studies, Frei et al. (2015) found significant increases to summertime precipitation in the Northeast United States. Similarly, rainfall variability and intensity has been increasing in the southeastern United States during the boreal summer (Wang et al. 2010; Weaver et al. 2016).

Case studies of impactful precipitation events have focused on improving the prediction or understanding of particular features. Marciano and Lackmann (2017) explored the contribution of Hurricane Joaquin to excessive rainfall and resultant flooding in South Carolina during October 2015 and concluded the hurricane slowed the progression of the upper-level trough and provided diabatic enhancement of the jet streak in the southeastern United States. These features set the stage for excessive moisture flow into the region and a multiday heavy rainfall event. Similarly, Tennessee and Kentucky endured a costly 3-day extreme rainfall event during May 2010. Lynch and Schumacher (2014) analyzed the European Centre for Medium-Range Weather Forecasts (ECMWF) medium-range ensemble prediction system and found that ensemble members with weaker low pressures and a more elongated trough predicted the event the best. Under future climate change, a May 2010-like event may worsen in terms of total precipitation due to the increased water vapor content and stronger convective updrafts (e.g., Lackmann 2013; Reidmiller et al. 2018). Although these referenced events are not S2S events per se, these analyses identify processes and features that could play an important role in improving the understanding and prediction of aggregate precipitation extremes at S2S lead times.

Key characteristics of daily to subweekly extreme precipitation have been identified over several spatial domains: the CONUS as a whole (e.g., Zhao et al. 2017; Touma et al. 2018) and various subregions of the CONUS (e.g., Konrad 2001; Schumacher and Johnson 2006; Moore et al. 2015; Chiodi et al. 2016; Collow et al. 2016). These works noted particular patterns of precipitation characteristics (seasonality, spatial scale, etc.), anomalous geopotential heights, and/or enhanced moisture transport that result in extreme precipitation events. In a study of similar events, Flanagan et al. (2018) examined characteristic atmospheric patterns associated with extremely rainy periods (i.e., pluvial) in the U.S. Great Plains. The study found that the characteristic atmospheric patterns during pluvial years are driven by synoptic-scale processes rather than low-frequency features and also differ between the northern and the southern Great Plains. A recurring theme in many of these studies is that moisture and mechanisms for its transport play a major role in these events. As such, atmospheric rivers (ARs) were suggested as an important medium for moisture transport (e.g., Newell et al. 1992; Gershunov et al. 2017), and thus identifying ARs is useful to investigate moisture transport associated with extreme precipitation events (Wick et al. 2013; Guan and Waliser 2015). ARs are a key aspect of extreme precipitation events throughout the United States (e.g., Lavers and Villarini 2013; Rutz et al. 2015; Mahoney et al. 2016; Dong et al. 2018; Dettinger et al. 2018). Yet, we lack a complete understanding of the role ARs play specifically for longerterm precipitation extremes. The role of large-scale modes of climate variability in these extreme weather events remains to be quantified. Individual events, 
like the anomalously cold North American winter of 2013/14, have been connected to persistent highamplitude climate modes such as the North Pacific Oscillation (NPO) and western Pacific teleconnection pattern (Baxter and Nigam 2015). However, there has not been in-depth analysis into whether precursory features exist in mode indices for a collection of longerterm events, particularly for precipitation.

Given the increased emphasis on S2S predictive skill and the impactful nature of extreme precipitation, our study addresses some of the gaps in understanding in our knowledge of aggregate subseasonal extreme precipitation events in a first step toward the end goal of improving S2S prediction. More specifically, 14-day aggregate extreme precipitation events are analyzed for their fundamental characteristics in precipitation (e.g., seasonality, event variability, and accumulation distribution), synoptic features, and connections to large-scale modes of climate variability. A 14-day aggregate period is the beginning of the subseasonal time frame, thus chosen as a starting point for investigation into subseasonal extreme events. It should be noted that these are not subseasonal events in the sense of lead-time prediction. Rather, the duration of these aggregate extreme precipitation events places them in the subseasonal temporal scale. These extreme events are established in a regional framework, allowing for comparisons between regions within the CONUS and a better understanding of the evolution of subseasonal extreme precipitation in those regions. We hypothesize that the 14-day extreme precipitation events identified have similar synoptic features (i.e., anomalous troughing, jet streaks, and enhanced moisture transport) to daily events and climate indices favorable for aboveaverage precipitation, as past studies have indicated, but over a 2-week period.

The manuscript is organized as follows. Data and methods used in this study, including the event identification algorithm, are described in section 2. Section 3 presents the results of the composite analysis for synoptic features associated with these events, including anomalous troughing and ridging and AR activity. Precursors to 14-day extreme precipitation events, including lagged composites of height and wind fields and their association with modes of climate variability, are discussed in section 4 . A summary and discussion of results follow.

\section{Data and methods}

\section{a. Data}

Precipitation data are from Parameter-Elevation Regressions on Independent Slopes Model (PRISM), which provides daily precipitation from 1981 to the present across the CONUS with a $4 \mathrm{~km}$ resolution (Daly et al. 2000; PRISM Climate Group 2017). These temporal and spatial scales are sufficient to analyze 14-day extreme precipitation events and their synoptic characteristics. In particular, PRISM data have uniform coverage in the western CONUS, where other datasets may lack coverage/ resolution. We found PRISM to have a similar number of events as other reanalysis products (not shown). Atmospheric variables from the ECMWF interim reanalysis (ERA-Interim) daily data with a $2.5^{\circ} \times 2.5^{\circ}$ longitude-latitude resolution (Dee et al. 2011) are used to investigate the synoptic features associated with, and preceding, 14-day extreme precipitation events. Variables include geopotential heights, zonal winds, and specific humidity. The latter two variables are used to quantify integrated vapor transport (IVT), a measure of vertically integrated transport of moisture, calculated following the method of Dettinger et al. (2018) and others:

$$
\mathrm{IVT}=-\frac{1}{g} \int_{1000 \mathrm{hPa}}^{200 \mathrm{hPa}}\left(q \times \mathbf{V}_{h}\right) d p,
$$

where $\mathbf{V}_{h}$ is the horizontal wind, $q$ is specific humidity, and $g$ is the acceleration due to gravity.

As mentioned in the introduction, ARs are a common driver of extreme precipitation and single-day heavy rainfall. Here, we apply our own AR framework to 14-day extreme precipitation events. To achieve this, we use a database of ARs based on a detection algorithm developed by Guan and Waliser (2015). This 6-hourly algorithm includes three key requirements for ARs, which is based on groups of elevated IVT values. First, IVT must be greater than the 85 th percentile at a given point and greater than $100 \mathrm{~kg} \mathrm{~m}^{-1} \mathrm{~s}^{-1}$. Second, the mean AR IVT direction vector must be within $45^{\circ}$ of the orientation of the AR shape and have an "appreciable" poleward component. Third, the length of the AR must be greater than $2000 \mathrm{~km}$ and have a length-to-width ratio that is greater than 2. Every identified AR is given an axis, which is defined as the points along the center of the AR, and a shape, which is the area of anomalously high IVT associated with the AR.

In addition to synoptic variables, modes of climate variability are also explored to identify possible connections to and predictability of 14-day extreme precipitation events. The daily indices for the Arctic Oscillation (AO) (Thompson and Wallace 2000), NPO (Rogers 1981), North Atlantic Oscillation (NAO) (Wallace and Gutzler 1981), and Pacific-North American pattern (PNA) (Wallace and Gutzler 1981) are provided by the NOAA Climate Prediction Center (CPC) (https://www.cpc.ncep.noaa.gov/ products/precip/CWlink/). We also consider the MJO, with 
the phase and amplitude, via the Wheeler and Hendon (2004) index, of the MJO provided by the CPC. These indices were chosen based on previous studies linking climate modes to extreme precipitation events (e.g., Kenyon and Hegerl 2010; Jones and Carvalho 2012; Jiang et al. 2014; Baxter and Nigam 2015; Mundhenk et al. 2018; DeFlorio et al. 2019).

\section{b. Defining 14-day extreme precipitation events}

To examine extreme precipitation events across the CONUS, we developed an algorithm to identify these events. First, we compute the distribution of 14-day precipitation cumulative totals for each point using a running 14-day moving window from 14 January 1981 to 31 December 2010. We choose the 95th percentile of the distribution as the threshold to define extreme precipitation at each location. The use of the 95th percentile is a common threshold in studies investigating extreme precipitation and allows us to investigate impactful events (Alexander et al. 2006; Frei et al. 2015; Collow et al. 2016). Note that similar works also use days with a minimum precipitation threshold (e.g., Rivera et al. 2014; Collow et al. 2016; Hirata and Grimm 2017). When considering 14-day events, this consideration need not apply because of the longer temporal scale being analyzed.

Figure 1 illustrates a map of the 95th-percentile values of 14-day precipitation totals. We further divide the CONUS into six geographic regions to compare and contrast characteristic patterns associated with 14-day extreme precipitation events in different parts of the country. The six different regions in this study are the Northeast (NE), Southeast (SE), Great Lakes (GL), Great Plains (PL), Mountain West (MW), and West Coast (WC). The regions are chosen based on similarities in values of the 95th percentiles themselves, climate classifications given in Kottek et al. (2006), and geopolitical boundaries. Our regional breakdown is similar to other extreme precipitation studies (e.g., Slater et al. 2019; Saharia et al. 2017). While there are many methods of partitioning the CONUS into regions, the delineation chosen for this study allows for a set of largely recognized regions that are sizable enough to identify regional 14-day extreme precipitation events.

Within a regional framework, 14-day extreme precipitation events are identified with the following criteria and considerations (Table 1). First, the total area, based on the number of grid boxes meeting or exceeding their 95th-percentile threshold, is calculated for every 14-day moving window. If the total area exceeds 200000 or $300000 \mathrm{~km}^{2}$ (see Table 1), we consider that a possible event. The area thresholds, including regional differences between criteria, are set based on sensitivity

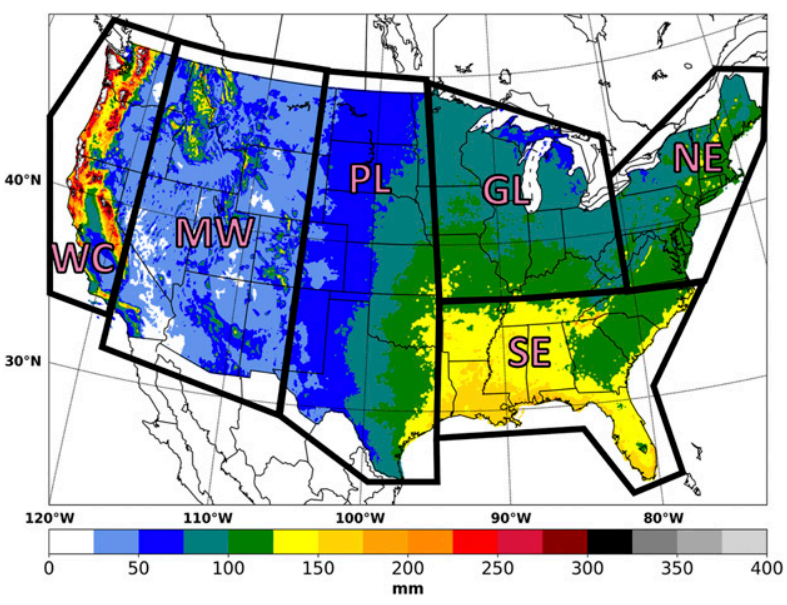

FIG. 1. The 95th percentile of the distribution for 14-day precipitation totals from 1981 to 2010 . The six regions of study for the CONUS are delineated by the black-outlined polygons.

testing with the goal of achieving a similar sample size between the regions. We then set two exclusionary criteria for events. First, if the number of days of areaaveraged precipitation exceeding $10{\mathrm{~mm} d a y^{-1}}^{-1}$ is less than 5 days ( 3 days in the MW), we exclude that event. This criterion ensures multiple days of precipitation during the period. With uniform criteria, we can insure a constant "precipitation day" in all regions, while defining an event by the 95th objective approach. Second, if the precipitation total for the day of the heaviest precipitation along with the day before and day after make up greater than $50 \%$ of the cumulative total precipitation for that 14-day period, the event is disregarded so as to avoid a smaller-temporal-scale event from being the leading driver of a 14-day event. Last, if any 14-day periods are overlapping with another event window, the 14-day window with the greatest cumulative precipitation is chosen so as not to have any events overlapping. Altogether, this approach ensures a comparable number of events in each region.

\section{c. Compositing methods}

With a list of 14-day extreme precipitation events for each region, composites of the ERA-Interim variables are then used to identify significantly anomalous patterns for each region. Three distinct time periods are chosen for compositing: 1) the 14 days during events (i.e., days +1 to +14 ), 2) days -10 to -6 , that is, before the start of a 14-day extreme precipitation event, and 3 ) days -5 to -1 . Patterns identified during the event window help to characterize the regional aspect of 14-day extreme precipitation events. Patterns before the start of the event are explored for their utility in forecasting such events with different leads. Statistical 
TABLE 1. 14-day extreme precipitation event criteria differences between regions, and the number of events analyzed in each region.

\begin{tabular}{lcccccc}
\hline & \multicolumn{5}{c}{ 95th-percentile 14-day events } \\
\cline { 2 - 6 } & NE & SE & GL & PL & MW & WC \\
\hline Area criteria $\left(\mathrm{km}^{2}\right)$ & $\geq 200000$ & $\geq 300000$ & $\geq 300000$ & $\geq 300000$ & $\geq 200000$ \\
No. of precipitation days & 5 & 5 & 5 & 5 & 3 & $\geq 200000$ \\
14-day event count & 28 & 36 & 36 & 41 & 5 \\
\hline
\end{tabular}

significance for composites is based on a 5000-iteration two-tailed bootstrapping test (with replacement).

Analysis of AR influences for 14-day extreme precipitation events is performed using the axis and shape features of the AR from the Guan and Waliser (2015) dataset. Using these two attributes, AR days are identified in each region to signify daily AR activity in a region to be on a consistent temporal period with other synoptic composites. For any one of the four 6-hourly time steps, if the AR axis is over land within a given region, and if the shape (i.e., the total area of the AR) is greater than $300000 \mathrm{~km}^{2}$ over land, then that day is considered an AR day. An AR day signifies an AR is making landfall and impacting the region. Our study examines the occurrence and significance of AR days during 14-day extreme precipitation event days and nonextreme event days.

\section{Characteristics of 14-day extreme precipitation events}

\section{a. Event statistics}

We begin our analysis of 14-day extreme precipitation events with an examination of the events themselves and their fundamental statistics. The number of events in each region ranges from 28 in the NE region to 41 in the PL region (Table 1), or approximately 1 event per year. Figure 2 presents a summary of distributions and statistics of the events per region. For the WC and MW regions, most 14-day extreme precipitation events occur during the extended boreal winter season (November-February) (Fig. 2a, green and pink bars, respectively). The PL and GL regions exhibit a bimodal seasonal distribution with a peak in frequency of events in June and again in early fall (Fig. 2a, gold and tan bars, respectively). Fourteen-day extreme precipitation events in the NE and SE regions are more evenly distributed throughout the year (Fig. 2a, red and blue bars, respectively), with maxima during boreal spring and fall. These seasonality aspects of 14-day extreme precipitation events generally align with the expected seasons for the wettest seasons in each area, as expected given how the 95th percentile is defined.

In terms of the yearly distribution of events (Fig. 2b), no long-term trends are apparent. Yet, some features stand out. First, the frequency of events is similar in all regions; that is, a fairly variable distribution throughout the 30 -yr period. All regions have some years with multiple events and some years with none. Second, several years stand out as particularly anomalous. Specifically in the PL and GL regions, 1993 is an exceptional year. All PL and GL events that year occurred between May and September (not shown), which correspond to the catastrophic Midwest flooding in the summer of 1993. Kunkel et al. (1994) identified specific multiday heavy precipitation events that contributed to the flooding and find above-average monthly precipitation in the upper Mississippi basin from April through August 1993 and in the greater upper Mississippi basin from April through September 1993. While there were several other factors that lead to the flooding (i.e., heavy winter precipitation and snowpack; Kunkel et al. 1994), the events found in our study are likely significant contributors to the extreme precipitation that year. By contrast, zero 14-day extreme precipitation events occurred in 1994. Last, 2007 was an overall very wet year in the PL region, where four events occurred, likely contributing to the pluvial year.

The differences in the distributions of precipitation during 14-day extreme precipitation events and the event-to-event coefficient of variation are displayed in Figs. $2 \mathrm{c}$ and $2 \mathrm{~d}$, respectively. A few observations are made from the distribution of event precipitation. First, the WC and SE regions have the greatest area-averaged precipitation (i.e., total area under the curve, Fig. 2c), while the MW region has the least. The three other regions have comparable totals to one another. This result corresponds well with the distribution of 95th percentile of 14-day precipitation totals (Fig. 1), with the regions of greatest thresholds receiving the greatest total precipitation. Second, precipitation is overall evenly distributed throughout 14-day extreme precipitation events in all regions, except for the SE region (Fig. 2c, blue line), suggesting that many events in the SE are an aggregation of a few "subevents," during which 1-3 days of heavier precipitation occur. The SE region also has the greatest coefficient of variation (Fig. 2d). By contrast, the WC region has the smallest coefficient of variation, suggesting that WC events have relativity less event-toevent variability in area-averaged precipitation totals 
a
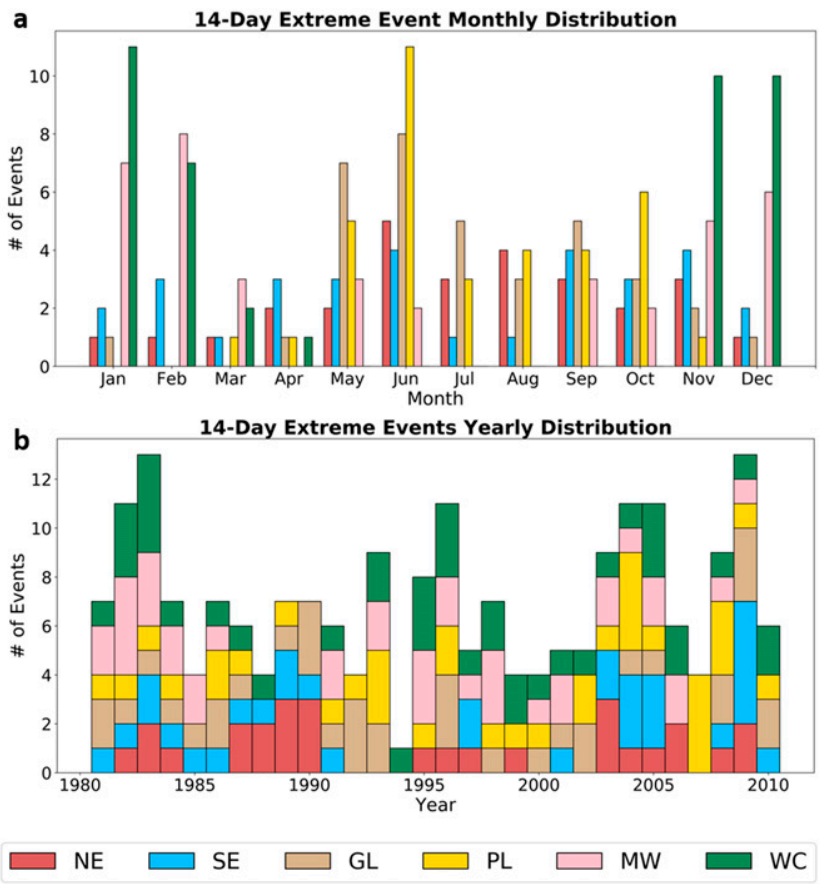

C

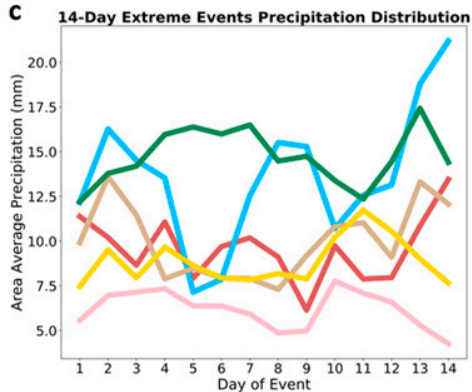

d 14-Day Extreme Events Coefficient of Variation
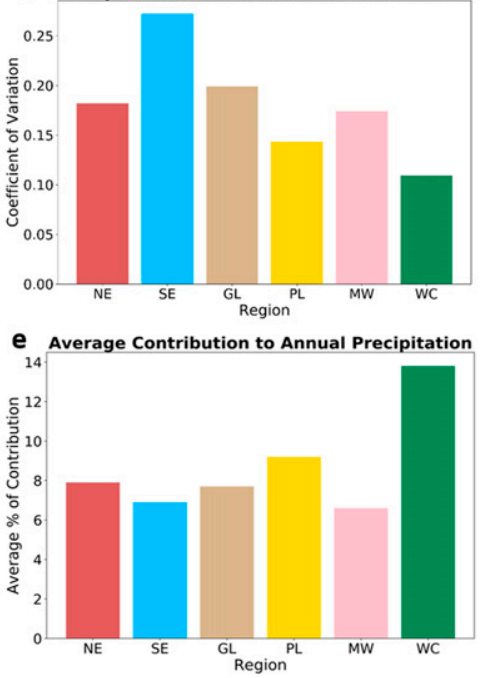

FIG. 2. Various statistical comparisons of regional 14-day extreme precipitation events: (a) monthly event distribution, (b) yearly event distribution, (c) composite of the distribution of area average precipitation for each day of the event, (d) coefficient of variation (standard deviation of events/mean rainfall per day), and (e) average event contribution to the annual precipitation total in each region.

than any other region. Furthermore, WC events have the greatest contribution to the regional annual precipitation totals (Fig. 2e). This comes as no surprise given the seasonal precipitation cycle in the region. From Fig. 2e, it is evident how an accumulation of events over a course of a year can contribute to pluvial years.

\section{b. Synoptic composites}

To examine the state of the atmosphere during 14-day extreme precipitation events, we composite daily standardized anomalies of several variables over the entire 14-day period for all events. These variables are standardized by subtracting the daily mean from the reanalysis value and dividing the subsequent value by the long-term (1981-2010) standard deviation. Figure 3 shows the average 500-hPa geopotential-height standardized anomalies in each of the six regions. All geopotential-height composites share a common theme: a trough-ridge pattern, with the trough (i.e., negative height anomalies) to the west of the specific region and ridging (i.e., positive height anomalies) to the east. The WC region is the exception, with a meridional dipole in the eastern Pacific (Fig. 3f). Furthermore, the relative magnitude of the trough-ridge pattern differs in each region. In the NE and WC regions (Figs. 3a,f, respectively), negative height anomalies are greater in magnitude than the corresponding positive height anomalies. The opposite is true in the GL region (Fig. 3c). These trough-ridge patterns are favorable for precipitation due to the positive differential vorticity advection, warm air advection promoting rising motion, and positive moisture advection over the region (Bluestein 1992). In a quasigeostrophic framework, the resulting ascent downstream of the $500 \mathrm{hPa}$ trough is supportive of the development of precipitation and has been tied to heavy rainfall (e.g., Maddox et al. 1979). Thus, a favorable synoptic geopotential-height pattern is in place in all regions during 14-day extreme precipitation events. 


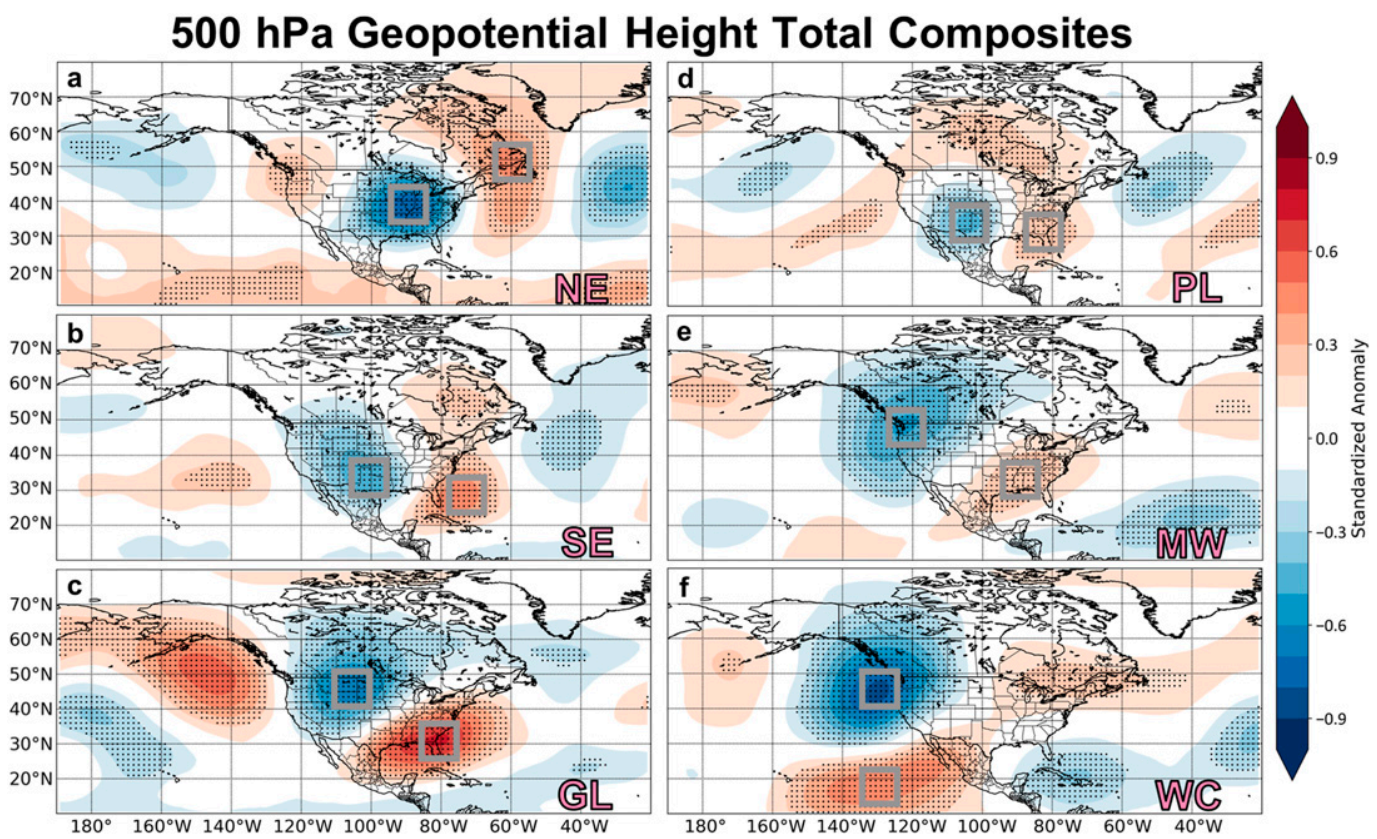

FIG. 3. Composite of 500-hPa geopotential-height standardized anomalies for extreme event days in each region. Significant anomalies, determined by a two-tailed Monte Carlo test with 5000 iterations and a $p$ value of 0.05 , are stippled. Gray-outlined boxes are $10^{\circ}$ by $10^{\circ}$ maxima areas for trough and ridge anomalies.

There is apparent nonuniformity in the exact orientation of the trough-ridge dipole, which is evident when examining the 200-hPa zonal wind standardized anomalies event composite (Fig. 4). The NE region composite (Fig. 4a) has an amplified zonal jet to the southwest of the region, putting the NE region in the left-exit region of a jet streak. The SE region (Fig. 4b) has the clearest jet streak feature with a maximum to the west and another to the northeast. This setup resembles an ideal coupled jet pattern, with the SE region located in the

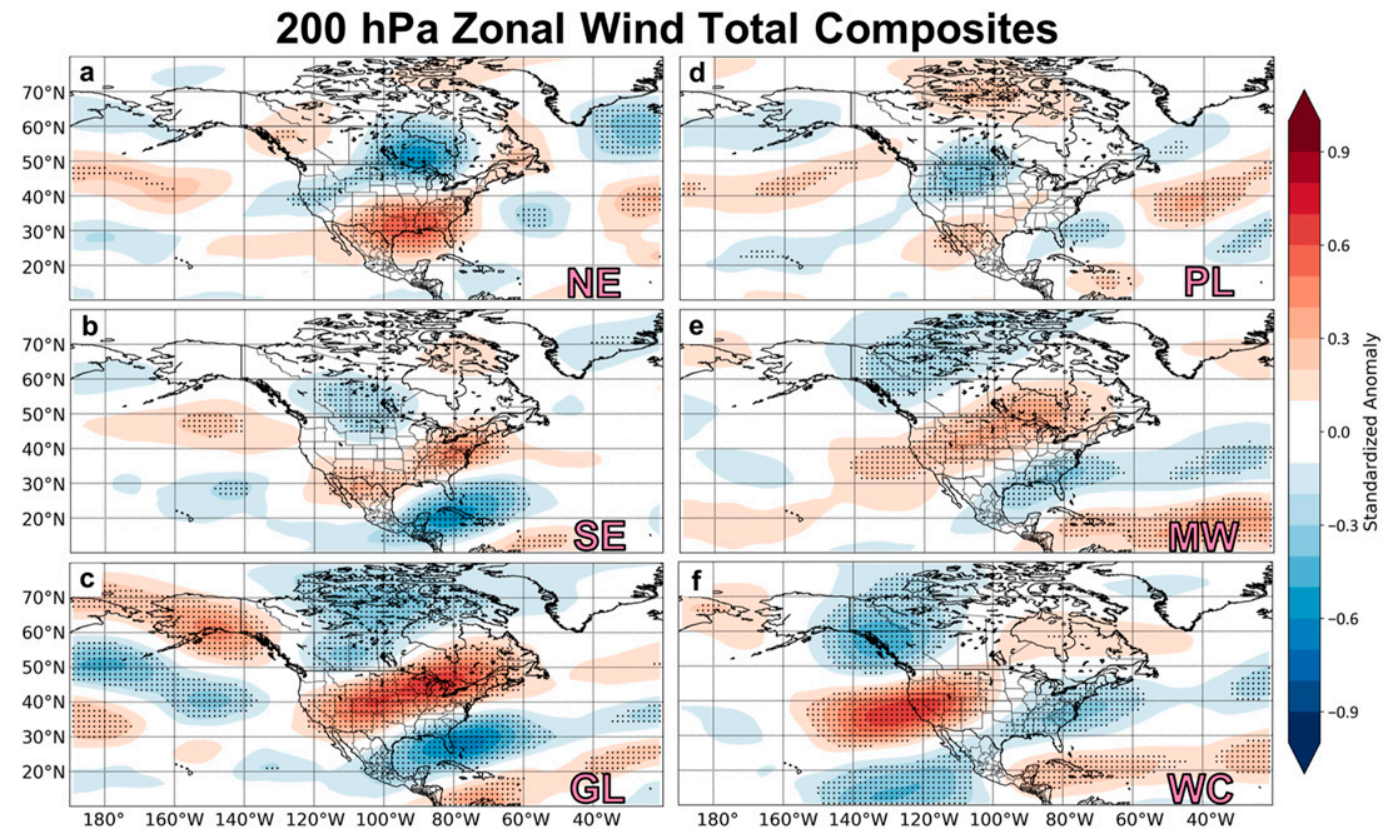

FIG. 4. As in Fig. 3, but for 200-hPa zonal winds. 


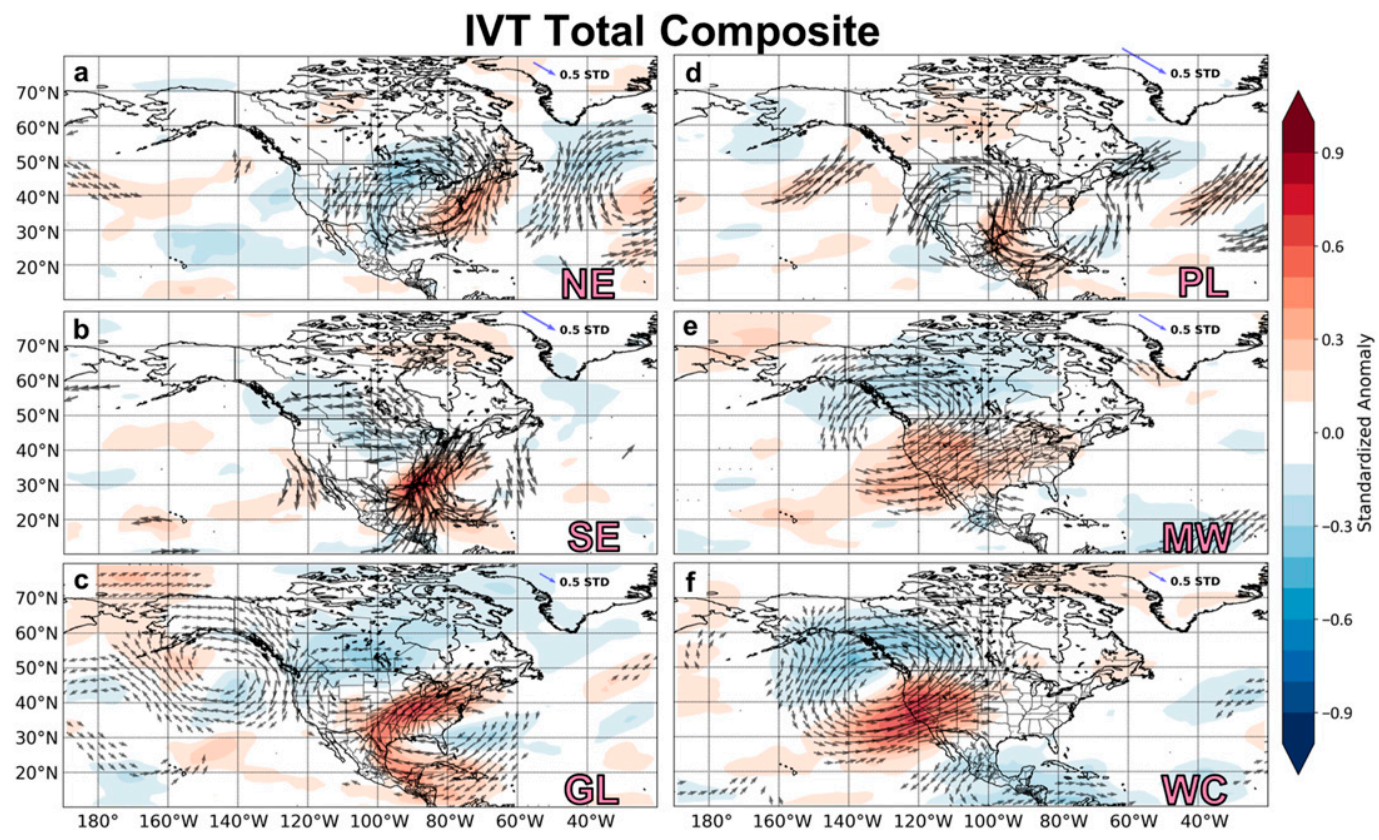

FIG. 5. Composite of standardized anomalies of IVT magnitude for extreme event days in each region (shading). Vectors depict the standardized anomalies of the $u$ and $v$ components of IVT. Only significant vector anomalies, determined by a two-tailed Monte Carlo test with 5000 iterations and a $p$ value of 0.05 , are plotted.

left-exit region of one jet and the right-entrance region of another. A coupled jet pattern favors upper-level divergence and synoptic-scale lift (Bluestein 1993). These upper-level zonal wind and midlevel height patterns point to a favorable dynamical set up for heavy preciplitation. The GL and WC regions (Figs. 4c,f, respectively) have the most pronounced anomalies, suggesting enhanced zonal winds are important and occur over a large area in 14-day extreme precipitation events. All regions except the PL region (discussed later) have significant zonal wind anomalies that are favorable for synoptically forced precipitation.

Enhanced moisture transport is also a main feature of 14-day extreme precipitation events. Figure 5 displays the total event composite of standardized IVT anomalies. Vectors overlaid on positive or negative anomalies respectively signify increased or decreased total column vapor transport in the direction of the vector. In all regions, large cyclonic and/or anticyclonic features set up in patterns favorable for enhanced moisture transport. The NE, MW, and WC regions (Figs. 5a,e,f) are dominated by cyclonic features collocated with troughing in those areas, suggesting that the synoptic-scale pattern drives the moisture transport. The SE, GL, and PL regions (Figs. 5b,c,d) exhibit large southerly anomalies with a clear moisture source in the Gulf of Mexico. There is also anomalous westerly flow in the east Pacific for the SE and PL regions, suggesting possible Pacific moisture influences for these regions. The $\mathrm{WC}$ region has some of the most anomalous IVT, implying flow from the central and eastern Pacific is fundamental for these events. In general, IVT anomalies indicate increased moisture transport into a region occurs during 14-day extreme precipitation events.

\section{c. Trough-ridge patterns}

The total event composites illustrate the importance of synoptic patterns for 14-day extreme precipitation events, particularly the prominent trough-ridge dipole pattern seen in all regions. To examine this prominent feature more closely, we construct indices for the standardized height anomalies in the trough and ridge maxima regions (the $10^{\circ}$ by $10^{\circ}$ boxes depicted in each panel of Fig. 3). Figures $6 a-d$ shows the resulting time series for the NE and WC regions. While other regions have similar time series and evolution, these regions are chosen to contrast the signals leading up to and during 14-day extreme precipitation events. Every day during the events in the NE region (Fig. 6a), the composite trough index indicates statistically significant $(p<0.05)$ negative anomalies. Over the same period, the standardized geopotential-height anomalies in the NE ridge index are positive but not always significant, suggesting the troughing feature dominates this region. Moreover, the trough signal appears up to 4 days before the start of the 14-day extreme precipitation event, but the ridge 

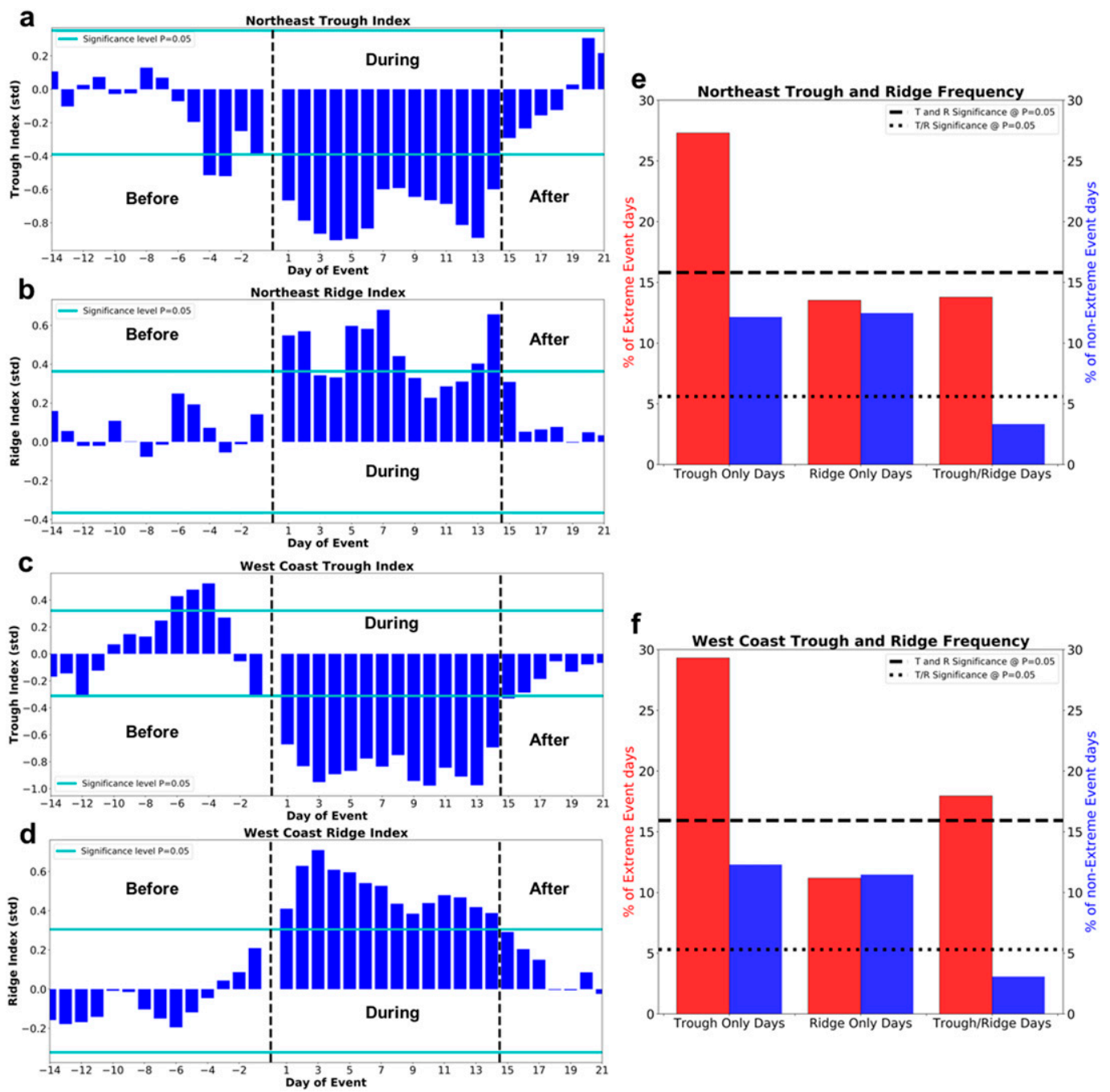

FIG. 6. Eulerian trough and ridge statistics based on the area average of geopotential-height anomalies in the gray boxes in Fig. 3. A time series of composites for the standardized anomalies for the (a) NE trough, (b) NE ridge, (c) WC trough, and (d) WC ridge areas before, during, and after events. Also shown are the percentages of occurrence of trough-only days, ridge-only days, and trough-ridge days for extreme event days (red) and nonextreme event days (blue) for the (e) NE and (f) WC; the level for a significant increase in percentage of occurrence, determined by a Monte Carlo test with 5000 iterations and a $p$ value of 0.05 , is dashed for trough-only and ridge-only days and dotted for trough-ridge days.

signal is absent until the event starts. The lack of ridging before the start of events suggests ridging is not a precursor to NE events but may develop as a result of the event.

The WC region trough and ridge time series (Figs. $6 c, d)$ are similar to those for the NE region during the events, but the WC region time series have greater magnitudes for the anomalies and a significant ridge signal during every day of the event. While the NE region has no signal beyond 4 days before the start of an event, the WC indices indicate strong ridging 4-6 days before the event in the WC region trough area and weak troughing
6-8 days before the event in the WC region ridge area. This reversal in geopotential-height anomalies preceding a 14-day extreme precipitation event is unique to the WC and could be a predictor of WC 14-day extreme precipitation events.

Figures $6 \mathrm{e}$ and $6 \mathrm{f}$ quantify the frequency of such anomalies relative to climatology via percentage of occurrence of trough and ridge days for event and nonevent days. (Nonevent days represent all other days in the 30-yr period that are not identified as event days.) Days in which the standardized anomaly is less than greater than $1 \sigma$ for the trough box are called 
trough-only days, and days in which the standardized anomaly is greater than $1 \sigma$ for the ridge box are called ridge-only days. A third separate classification quantifies days that meet both trough-only day and ridgeonly day criteria: that is, trough-ridge days. For the $\mathrm{NE}$, trough-only days are significantly more frequent during 14-day extreme precipitation events with troughonly days occurring in over $25 \%$ of event days, while ridge-only days occur in nearly $13 \%$ of event days. Trough-ridge days are also more frequent, with occurrence around $14 \%$ of event days as compared with just $3 \%$ in all other days. The WC region has more troughridge days than the NE region, likely resulting in a reduction of trough-only and ridge-only days. Adding the trough-ridge days and the trough-only days together, the WC region has anomalous troughing in the designated region on over $45 \%$ of 14-day extreme precipitation event days. Furthermore, in both the WC and NE regions, trough-only days are more frequent, and troughing indices are more anomalous than their ridge counterparts (Figs. 6a-d), indicating that midlevel troughing plays a more important role than ridging in these regions. In fact, the preeminent role of troughing is found in all regions, except for the GL region where the southeast ridge seems to be a bigger influence on 14-day extreme precipitation events (not shown). Note that these periods of enhanced troughing and ridging, while shown to be important for these events, are not particularly unique to extreme precipitation events. A significant increase in trough-ridge days does not necessarily result in a 14-day extreme precipitation event. Amplified trough-ridge dipoles can also be associated with nonextreme precipitation, similar to the findings in Zhao et al. (2017).

\section{d. Atmospheric rivers}

We next explore how ARs contribute to 14-day extreme precipitation events in the CONUS. Figure 5 illustrates that anomalous IVT into a region is a prevailing characteristic of 14-day extreme precipitation events, which has a close connection to ARs (Newell et al. 1992). AR days, a proxy for landfalling AR activity, are calculated in each region using the Guan and Waliser (2015) AR database. Figure 7a compares the frequency of AR activity during event and nonevent days, again where nonevent days are all other days in the 30 -yr period that are not identified as event days. All regions have an increase in AR days during extreme event days than nonextreme days. The NE, SE, and WC regions have the smallest percentages of AR days for nonevent days, but Guan and Waliser (2015) find these areas of the United States have higher AR frequency than the GL, PL, and WM regions. Thus, we need to compare the differences between
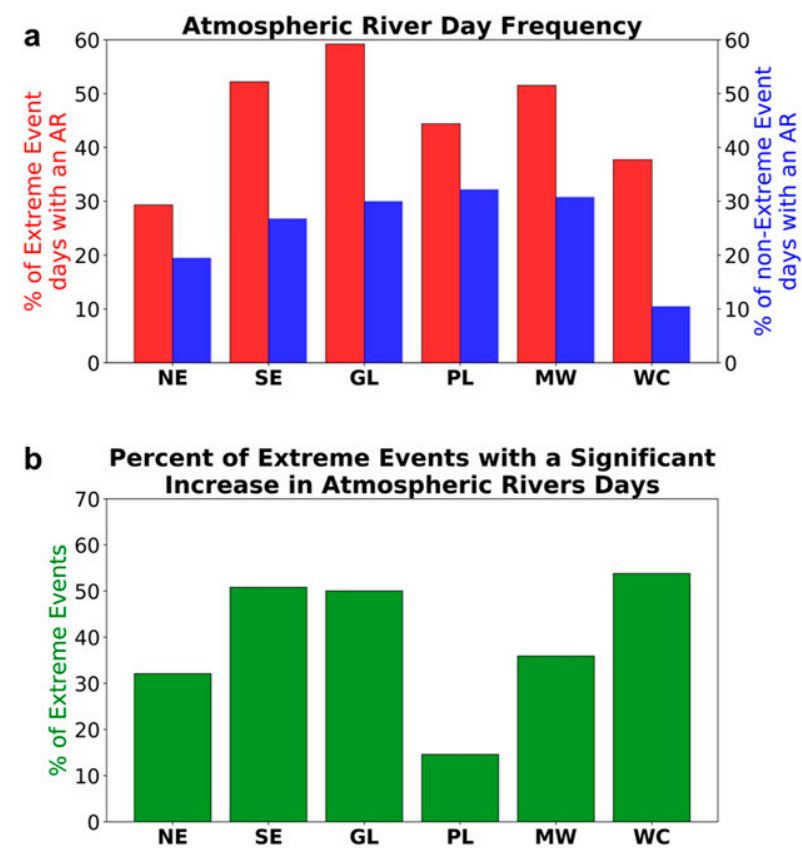

FIG. 7. (a) The percentage of occurrence of AR days during extreme events (red) and nonextreme events days (blue) in each region. (b) The percentage of 14-day extreme precipitation events with a significant increase in number of AR days in each region. Significant number of AR days is determined by a Monte Carlo test with 5000 iterations and a $p$ value of 0.05 .

the event AR days and the nonevent AR days to get a better sense of the changes in AR frequency. The WC, GL, and SE regions have the greatest of the differences, suggesting that AR frequency increases the most in these areas.

Next, we examine the significant number of AR days during our 14-day extreme precipitation events by computing the average number of AR days and determining the number of AR days that constitutes a significant increase. An exceedance of this value represents an anomalous increase in ARs in a 14-day period. Figure $7 \mathrm{~b}$ shows the percentage of our 14-day extreme precipitation events that meet or exceed the significant value. For example, it can be said that $50 \%$ or 18 of the $36 \mathrm{GL}$ events have a significant number of AR days. The analysis indicates that AR frequency tends to increase during 14-day extreme precipitation events. The greatest increase in AR frequency occurs in the SE, GL, and WC regions. With $\geq 50 \%$ of events corresponding to a significant increase in AR activity, ARs are a particularly important characteristic of 14-day extreme precipitation events in these three regions. This result is in agreement with Figs. 5c and 5f, where the SE, GL, and WC regions have the most anomalous IVT into their respective region. 


\section{0 hPa Geopotential Height Lagged Composites}
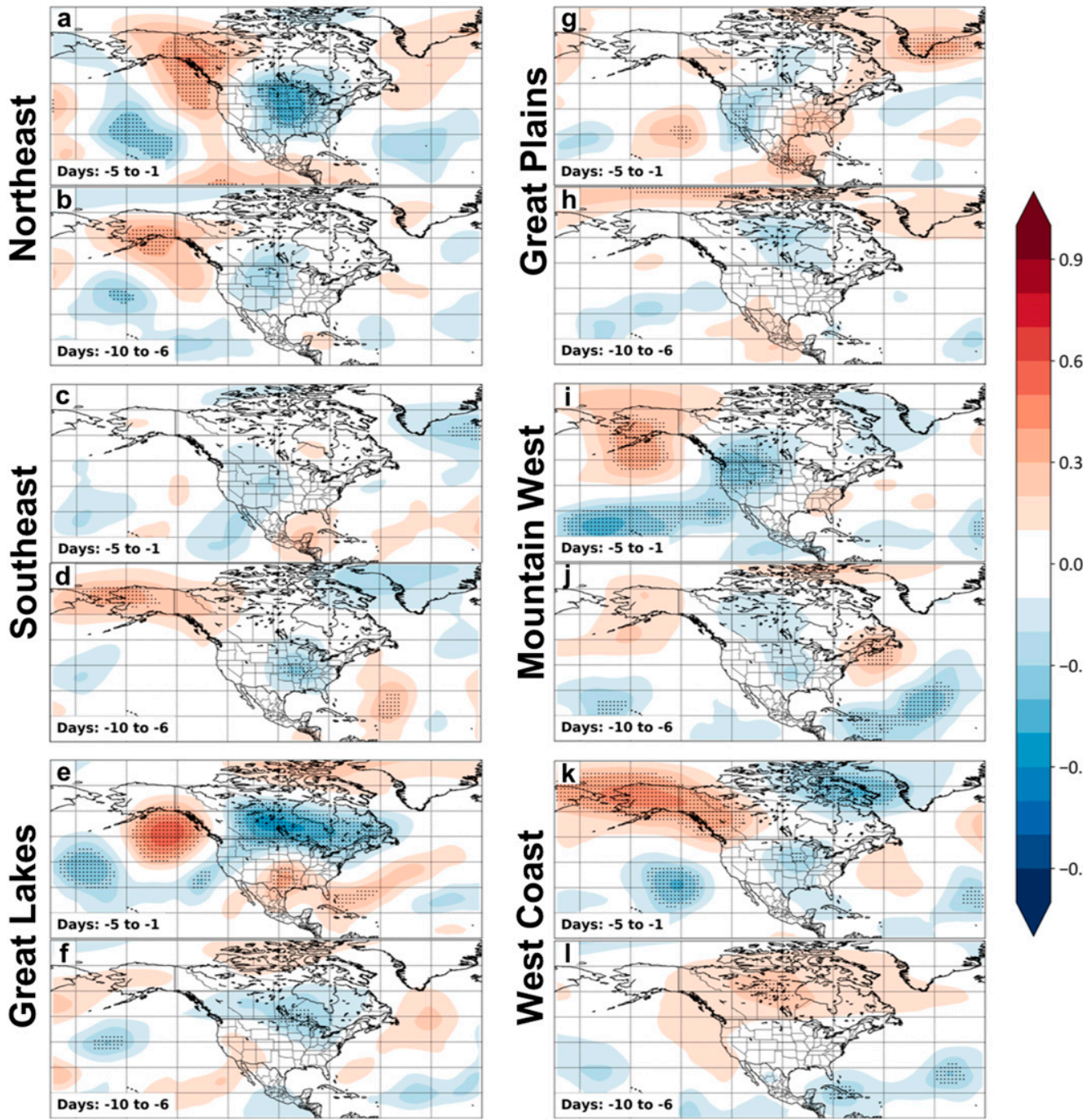

0.9

0.6

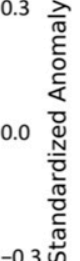

FIG. 8. Composite of 500-hPa geopotential-height standardized anomalies for lagged windows of -10 to -6 and -5 to -1 days (before the first day of an extreme event). Significant anomalies, determined by a two-tailed Monte Carlo test with 5000 iterations and a $p$ value of 0.05 , are stippled.

\section{Precursors to 14-day extreme precipitation events}

Thus far, we have examined fundamental atmospheric characteristics that occur during a 14-day extreme precipitation event for various regions in the CONUS. As Figs. 6a-d indicate, however, some regions have synoptic patterns in place before events begin. In this section, we analyze lag composites of synoptic variables to reveal whether there are significant atmospheric precursors to 14-day events, which could improve the skill of forecasting these events. We also examine several modes of climate variability for their possible use in the prediction of 14-day extreme precipitation events.

\section{a. Synoptic lag composites}

Figure 8 displays averaged $500-\mathrm{hPa}$ geopotentialheight standardized anomalies for each of the six regions for both day -10 to -6 and day -5 to -1 (day -1 represents the day before the start of the 14-day extreme precipitation event). In the day -5 to -1 window, several regions feature similar patterns to their corresponding total event composites (Fig. 3). All regions except the $\mathrm{WC}$ region have similar trough and ridge anomalies to their event composites, but with anomalies shifted upstream to the west and northwest of the locations seen in Fig. 3. The NE region (Fig. 8a) features a developing trough in the western Great Lakes but lacks 


\section{$200 \mathrm{hPa}$ Zonal Wind Lagged Composites}
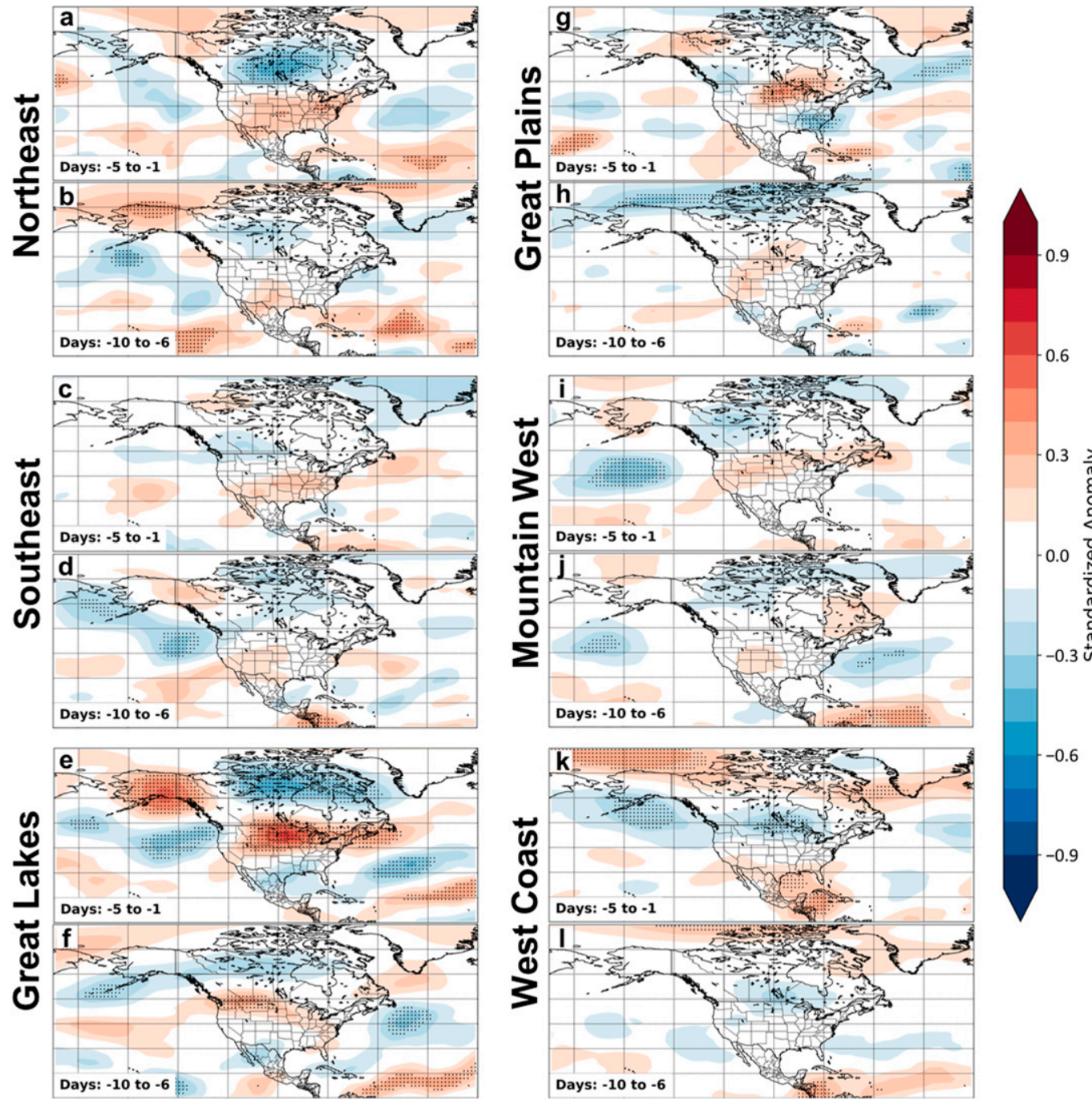

FIG. 9. As in Fig. 8, but for 200-hPa zonal winds.

the downstream ridge noted in Figs. $6 \mathrm{a}$ and $6 \mathrm{~b}$. The WC and MW regions (Figs. 8i,k) both show meridional dipoles in the form of an Alaskan ridge and North Pacific trough. Ridging over Alaska and in the Gulf of Alaska is a common feature in several regions, but particularly in GL region during the day -5 to -1 window (Fig. 8e).

In looking farther back to days -10 to -6 (Figs. $8 \mathrm{~b}, \mathrm{~d}, \mathrm{f}, \mathrm{h}, \mathrm{j}, \mathrm{l})$, it is seen that the CONUS itself is void of any statistically significant geopotential-height anomalies. Again, the Alaskan ridge signal emerges as a significant precursor for 14-day extreme precipitation events in the NE, SE, and MW regions (Figs. 8b,d,j). The reversal in polarity of the height dipole in the $\mathrm{WC}$ region identified in Figs. $6 \mathrm{c}$ and $6 \mathrm{~d}$ is depicted in the day -10 to -6 composite as well, albeit much weaker in magnitude. Increased event-to-event variability in synoptic flow likely contributes some to the weakening in the strength of the signals in this window.

The same lag composite analysis is performed on $200 \mathrm{hPa}$ zonal wind in Fig. 9. Days -5 to -1 compositemean zonal wind patterns correspond less to the event total composite patterns (Fig. 4) than the geopotentialheight composites. The GL and MW regions (Figs. 9e,i) are the only two that resemble the total event composites (Figs. 4c,e), though the GL region is the only region of the two with statistically significant anomalies (Fig. 9e). In the GL region, an amplified jet is located over the north-central United States and Alaska, suggesting an active synoptic weather pattern. This notion is supported by the day -5 to -1 geopotential-height anomaly 

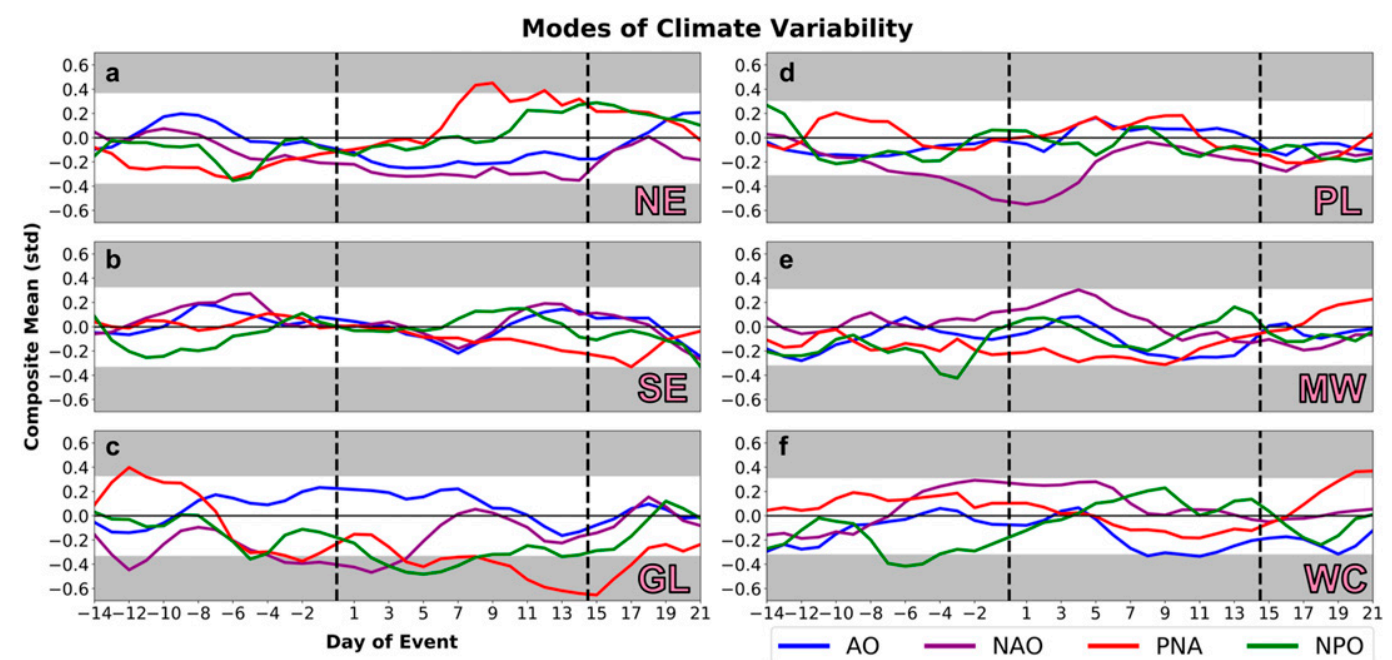

FIG. 10. Lag composite time series for the AO (blue), NAO (purple), PNA (red), and NPO (green) (standardized) before, during, and after 14-day extreme precipitation events as a function of region. The level for significance $(p<0.05)$ is denoted by gray background shading, as determined by the most robust level of the four time series.

composites for the GL region (Fig. 8e). Additionally, the MW and WC regions (Figs. 9i,k) both feature anomalously weak zonal winds near or south of the Gulf of Alaska. The weaker zonal winds, along with their respective geopotential-height composites (Figs. 8i,k), suggest a developing Alaskan ridge before 14-day extreme precipitation events begin for the two westernmost CONUS regions.

As in Fig. 8, the day -10 to -6 composites (Figs. $9 \mathrm{~b}, \mathrm{~d}, \mathrm{f}, \mathrm{h}, \mathrm{j}, \mathrm{l})$ exhibit weak zonal wind anomalies, likely due to increased variability in synoptic flow. The GL region (Fig. 8f) features the only significant anomaly over the CONUS, which is similar to the amplified jet in the day -5 to -1 composite (Fig. 9e) but with reduced magnitude. Several regions (e.g., NE, SE, GL, and MW) feature weak zonal wind anomalies in the North Pacific in their day -10 to -6 composite means (Figs. 9b,d,f,j), suggesting patterns conducive to CONUS 14-day extreme precipitation events may develop upstream several days before events begin in some cases.

\section{b. Modes of climate variability}

To examine the utility of large-scale climate modes in forecasting 14-day extreme precipitation events across the CONUS, we conduct lag composite analysis on the standardized indices of four key climate modes for U.S. weather variability: the AO, the NAO, the PNA, and the NPO (Fig. 10). While never reaching statistical significance, an AO signal appears in the NE and GL regions (Figs. 10a,c), with a positive AO 12 to 5 days before 14-day extreme precipitation events begin in the $\mathrm{NE}$ region turning slightly negative during the event. In the GL region, the AO is positive about a week before the start of 14-day extreme precipitation events and stays positive until the final days of the event. Interestingly, the normally closely related NAO is out of phase with the $\mathrm{AO}$ in the GL region, particularly near the start of the 14-day extreme precipitation events, when it becomes significantly negative. Anomalously high heights over the North Atlantic and troughing over eastern North America, a blocking pattern commonly associated with a negative NAO, would suggest increased precipitation in the GL region, but is not clearly identified in Fig. 3c. The opposing signs of the NAO and AO suggests a more active synoptic pattern, possibly the result of with more short-wave activity, is in place over North America, while a more zonal flow is in place over the rest of the Northern Hemisphere. The region with the strongest and most significant NAO signal is the PL region (Fig. 10d), where a negative composite mean index value occurs near the start of 14-day extreme precipitation events. This significant negative NAO signal again suggests downstream blocking occurs toward the beginning of events. Both the MW and WC regions (Figs. 10e,f) have a generally positive NAO. Although far from the North Atlantic, downstream blocking may support slowed synoptic-wave propagation upstream, keeping these regions in a troughing dominated regime.

The PNA possesses detectable signals for several regions. A positive PNA (characterized by troughing in the North Pacific, ridging in western North America, and troughing in the eastern United States) pattern 


\section{MJO Phase Preceding/During EEs (AMP>1.0)}
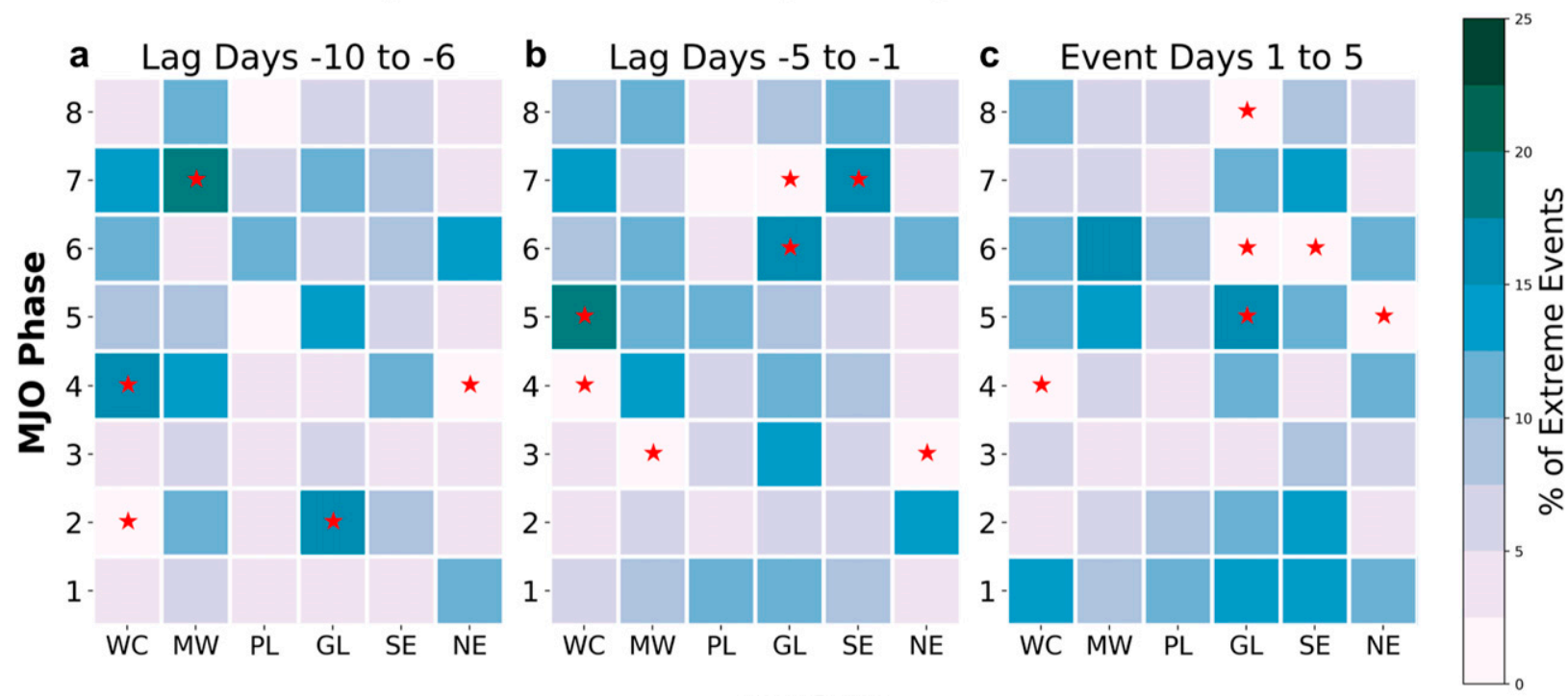

Regions

FIG. 11. Heat map of MJO phase occurrence in each region for lag windows of (a) -10 to -6 days, (b) -5 to -1 days, and (c) the first five days of the event. The daily MJO phase is based on the Wheeler and Hendon (2004) Real-time Multivariate MJO series 1 (RMM1) and 2 (RMM2). To determine the MJO phase during the 5-day windows, the mode is chosen as the window phase if it occurs in at least three of the five days. Only windows with an average 5-day amplitude of $\geq 1.0$ are considered. Red stars indicate that the composite percentages of occurrence for MJO phases before/during 14-day extreme precipitation events are significantly different than the mean percentage of occurrence of particular phases (roughly $7 \%-8 \%$ ). This significance test is based on a two-tailed bootstrapping test ( $p$ value of 0.05 ), with 5000 iterations and assists in identifying common and uncommon phases of the MJO before and during events.

exists during events in the NE region (Fig. 10a) and precedes events in the GL, PL, and WC regions (Figs. 10c,d,f). The significant positive PNA signature makes sense for the NE region given the characteristic troughing patterns in its corresponding height composite (Fig. 3a). The height anomaly patterns for the GL region (Fig. 3c) during 14-day extreme precipitation events match remarkably well with the PNA pattern. Indeed, the notion that the ridge-trough-ridge pattern in the GL region closely resembles the characteristic negative PNA pattern is supported by the negative PNA signal in Fig. 10c. The last mode of climate variability considered is the NPO, which has the greatest connection to 14-day extreme precipitation events in the GL and WC regions (Figs. 10c,f). A negative NPO signal is apparent throughout the 14-day event period in the GL region and is significantly negative for several days during events, likely a link to the anomalously high geopotential heights in the North Pacific (Fig. 3c). In the WC region, the NPO shifts from negative to positive near the start of events. The North Pacific $500 \mathrm{hPa}$ height pattern for the WC region composite features a meridional dipole pattern like that of the positive phase of the NPO, albeit displaced to the southeast (Fig. 3f). As previously discussed, there is a reversal in the height patterns for the WC regions (Figs. 6c,d). This change in height anomalies mirrors the flip from negative NPO to positive NPO (Fig. 10f). While not applicable in every event, these modes of climate variability may have some connection to 14-day extreme precipitation events due to their corresponding synoptic anomaly patterns.

Last, we consider the ties between the MJO and our 14-day extreme precipitation events. This teleconnection pattern may influence North American precipitation through Rossby wave propagation into the midlatitudes causing changes to storm tracks and hence precipitation anomalies (e.g., Zheng et al. 2018). The link between the MJO and subseasonal precipitation across North America may help to improve the prediction of extreme precipitation (Jones et al. 2004; Jones and Carvalho 2012). Figure 11 presents heat maps of MJO phase lag composites for days -10 to -6 (Fig. 11a), days -5 to -1 (Fig. 11b), and days +1 to +5 (Fig. 11c). Although several MJO phases are statistically significant for different regions, one major finding is that there is an absence of a true "evolution" of the MJO; that is, where the MJO advances sequentially in phase with time. While we would not expect any signal in days $1-5$ of the event (Fig. 11c) during phases associated with suppressed precipitation, we may expect some signals in 
phases preceding precipitous phases in the lag days -10 to -1 (Figs. 11a,b). Although Fig. 11 shows several regions have statistically significant MJO phases, the field significance needs to be considered. This may account for some of the significant points that lack a physical explanation. Investigating relationships between phases and periods of occurrence could help separate significant signals from false discovery. MJO phases 6 and 7 are more common during days -10 to -6 and phases 5 and 6 are more common during days -5 to -1 over all regions versus other phases. Phases 1-3 are the less common MJO phases preceding 14-day extreme precipitation events. During the first five days of the event, phases 1,5, and 6 are more common than phases 3,4 , and 8 .

From a regional perspective, the $\mathrm{WC}$ region has the most common MJO phase progression from phase 4 to phase 5 to no significant phase during events (Fig. 11). Mundhenk et al. (2018) suggests a connection between increased AR activity in California in the few days after an MJO phase-7 event. This analysis neither confirms nor rebuts this suggestion, because the frequency of MJO phase-7 events is insignificant for the WC region for all lags. However, for the WC region, MJO phase 7 is more common before events than during events. Meanwhile, MJO phase 7 is significantly more common in the MW region during the -10- to -6-day lag window. The GL region has aspects of some progression between phase 2 and phase 5 from days -10 to -6 lag to days +1 to +5 . Outside these two regions, there are no identifiable patterns of MJO phase propagation. The features identified in Fig. 11 may have some use in aiding prediction of extreme precipitation, but the complex nature of these 14-day extreme precipitation events prohibit a stronger correlation.

\section{Summary and discussion}

In summary, extreme precipitation events have considerable societal impacts, leading to a need for greater understanding and better prediction of them. While many studies have focused on daily extreme precipitation and individual synoptic systems, investigation into longer-term events, including in the S2S time frame, is lacking. Analyzing relatively large-scale 14-day extreme precipitation events based on the 95th percentile of precipitation, among other considerations, constitutes a first step into understanding S2S, particularly subseasonal, precipitation extremes. Working with specific predefined regions within the CONUS also allows for more accurate representations of regional drivers of these events.

Fourteen-day extreme precipitation events vary seasonally, similarly to each region's annual precipitation cycle (Fig. 2a). General synoptic patterns that characterize a 14-day extreme precipitation event include a $500-\mathrm{hPa}$ trough-ridge dipole with the trough axis positioned to the west of the region of interest (Fig. 3). The location of the greatest positive height anomaly with respect to the event area varies by region. Troughing is more frequent than ridging in the NE and WC regions (Fig. 6). This dominance of the troughing feature is apparent in all regions outside the GL region, where the southeastern U.S. ridge appears to be most prominent. Furthermore, an anomalous increase in $200-\mathrm{hPa}$ zonal winds and IVT into each region provides a favorable setup for synoptic-scale precipitation, as shown in Figs. 4 and 5, respectively. Last, there is a significant uptick in the AR frequency for each region, with the SE, GL, and WC regions having the greatest increase (Fig. 7). These synoptic characteristics are similar across the CONUS, except the exact setup varies from region to region.

Identifying significant, large-scale precursor features of 14-day extreme precipitation events produced mixed results. Features in composite anomalies of $500-\mathrm{hPa}$ geopotential height (Fig. 8) and 200-hPa zonal wind (Fig. 9) were apparent in many regions in the day -5 to -1 lag window including ridging and zonal wind anomalies in the North Pacific. In the day -10 to -6 day window, statistically significant anomalies are confined to the North Pacific where varying jet and height patterns occur (Figs. 8 and 9b,d,f). A few regions have detectable signals in the indices of the four modes of climate variability examined in this study. A positive PNA in the GL region (Fig. 10c), a negative NAO in the PL region (Fig. 10d), and a trend toward more a more positive NPO in the WC region (Fig. 10f) are the most robust signals from our analysis. Other significant signals observed in the figure may result from false discovery and may not be robust. For the MJO, phases 5-7 have the greatest occurrence in the event days $1-5$ in Fig. 11c, but our findings lack a true sequential progression of MJO phase. Unfortunately, the composites of these modes do not diagnose clear precursors for our 14-day extreme precipitation events.

Many aspects of these results agree with previous literature on extreme precipitation. The location of the troughing with relation to the precipitation area is similar to 500-hPa cyclone centers in Konrad's (2001) analysis of 2-day extreme precipitation events. The anomalously high heights to the northeast of the NE region is more of a downstream ridge compared to other regions (Fig. 3a), suggesting that this ridge could be amplified by advecting diabatic heat released from the condensing precipitation over the NE (e.g., Aubert 1957). This is one possible explanation for the lagging precursor signal in the ridge index (Fig. 6b). Furthermore, 
the upstream ridge signal disappears quickly after the event has ended, again suggesting a close association with NE region precipitation.

In addition, Konrad (2001) suggested other aspects of the synoptic environment, beyond 500-hPa troughing, are necessary for extreme precipitation, such as moisture advection and wind direction. In addition to geopotentialheight anomalies, our study identifies some of these additional aspects including enhanced IVT, strong upper-level zonal winds, and increased AR frequency. Although their precipitation regions were determined by hierarchical clusters, the orientation of the trough ridge dipoles in Zhao et al. (2017), along with the cyclonic and anticyclonic IVT anomalies, fit patterns seen in this analysis (i.e., Fig. 3). The percentage of ARs days during extreme precipitation events in the SE are similar to work done by Mahoney et al. (2016), which found between $40 \%$ and $60 \%$ (varying seasonally and spatially) of daily events in the southeastern United States were associated with a an AR. Likewise, nearly $60 \%$ of 14-day event days correspond with ARs in the GL region (Fig. 7), supporting the $60 \%-70 \%$ AR connection to annual maxima floods in a similar region (e.g., Lavers and Villarini 2013). Links between 14-day extreme precipitation events and modes of climate variability are more tenuous in our work, however, making it difficult to connect our results with those from previous literature.

This work represents a first look at 14-day extreme precipitation events and, as such, contains several caveats that should be addressed. Although many regions exhibit seasonality in event distributions, the lack of seasonal considerations explicitly in this work may lead to less anomalous indices of modes of climate variability. Touma et al. (2018) concluded that different CONUS regions have differing scales of precipitation, depending on the season, and Zhao et al. (2017) identified differences in the magnitude of synoptic patterns between the warm and cold season in the CONUS. Furthermore, seasonal considerations for modes of climate variability would help connect modes to their seasonal patterns of geopotential-height and precipitation anomalies. For example, considering only cool-season events, when the $\mathrm{NAO}$ is most active, could offer additional statistically significant connections. The regions themselves may also play a role in some variability in results. While the regions chosen for our study are expansive enough to capture large-scale events, precipitation characteristics may not be the same throughout a specific region. For example, Flanagan et al. (2018) identified different features in the northern Great Plains as compared with the southern Great Plains for pluvial years. The patterns identified in this study ignore the differences between these two areas, yet they are similar in scale and orientation to the ones found in Flanagan et al. (2018). Additionally, signals found for WC region events may muddled due to the large meridional extent of the region. Mundhenk et al. (2018) finds differing results for the modulation of ARs by the MJO between the Pacific Northwest and California. Furthermore, a strict boarder for each region does not allow for events that occur between regions to be identified. This facet may impact event counts in each region.

Observed in the PL region, magnitudes for synoptic features during 14-day extreme precipitation events (Figs. 3d-5d) are less than those in other regions. This difference in magnitude may be attributed to differences in precipitation characteristics, such as precipitation drivers and their overall scale. For instance, Great Plains extreme precipitation relies more on mesoscale convective systems (MCSs) than synoptic forcing (Schumacher and Johnson 2006), with parts of the region receiving over $60 \%$ of their May-August rainfall from MCSs (Haberlie and Ashley 2019). This strong reliance on MCSs for high precipitation totals would account for weaker synoptic anomalies in the PL and support our finding that 14-day extreme precipitation events in the PL region peak in the warm season (Fig. 2a), when MCSs are more common.

Several avenues of future work exist for understanding and predicting 14-day extreme precipitation events. For example, we are still unsure what the exact drivers of precipitation (i.e., MCSs, tropical systems, and synoptic isotropic ascent) are most favorable for each region. Further, additional investigation into precursors for extreme precipitation and the utility of numerical, statistical, and operational subseasonal dynamical prediction models could inform us more about the actual predictability of these events, including lead times. Last, we are currently examining extreme precipitation events on other S2S periods (e.g., 30-, 60-, and 90day) with a goal of cataloguing these events. Preliminary work on 30-day extreme precipitation events shows somewhat similar precursor anomalies to 14-day events, including the significant trough-ridge signals in each region. These findings will be presented in a future study.

Acknowledgments. The authors thank the other members of the PRES ${ }^{2}$ iP research group for their contributions. We also thank the three anonymous reviewers for their feedback and edits. This work is supported by the National Science Foundation under their Prediction of and Resilience against Extreme Events (PREEVENTS) program (Grant ICER-1663840).

\section{Data availability statement:}

PRISM precipitation data are provided by the PRISM Climate Group (http://prism.oregonstate.edu). ERAInterim data used in this study are available online 
(http://www.ecmwf.int). The AR data are provided by Bin Guan (https://ucla.box.com/ARcatalog).

\section{REFERENCES}

Alexander, L. V., and Coauthors, 2006: Global observed changes in daily climate extremes of temperature and precipitation. J. Geophys. Res., 111, D05109, https://doi.org/10.1029/2005JD006290.

Armal, S., N. Devineni, and R. Khanbilvardi, 2018: Trends in extreme rainfall frequency in the contiguous United States: Attribution to climate change and climate variability modes. J. Climate, 31, 369-385, https://doi.org/10.1175/JCLI-D-170106.1.

Aubert, E. J., 1957: On the release of latent heat as a factor in large scale atmospheric motions. J. Meteor., 14, 527-542, https:// doi.org/10.1175/1520-0469(1957)014<0527:OTROLH >2.0. $\mathrm{CO} ; 2$.

Baxter, S., and S. Nigam, 2015: Key role of the North Pacific Oscillation-west Pacific pattern in generating the extreme 2013/14 North American winter. J. Climate, 28, 8109-8117, https://doi.org/10.1175/JCLI-D-14-00726.1.

Bluestein, H. B., 1992: Principles of Kinematics and Dynamics. Vol. 1, Synoptic-Dynamic Meteorology in Midlatitudes, Oxford University Press, $431 \mathrm{pp}$.

_ 1993: Observations and Theory of Weather Systems. Vol. 2, Synoptic-Dynamic Meteorology in Midlatitudes, Oxford University Press, 594 pp.

Brunet, G., and Coauthors, 2010: Collaboration of the weather and climate communities to advance subseasonal-to-seasonal prediction. Bull. Amer. Meteor. Soc., 91, 1397-1406, https://doi.org/ 10.1175/2010BAMS3013.1.

Chiodi, A. M., N. A. Bond, N. K. Larkin, and R. J. Barbour, 2016: Summertime rainfall events in eastern Washington and Oregon. Wea. Forecasting, 31, 1465-1480, https://doi.org/ 10.1175/WAF-D-16-0024.1.

Collow, A. B. M., M. G. Bosilovich, and R. D. Koster, 2016: Largescale influences on summertime extreme precipitation in the northeastern United States. J. Hydrometeor., 17, 3045-3061, https://doi.org/10.1175/JHM-D-16-0091.1.

Daly, C., G. H. Taylor, W. P. Gibson, T. W. Parzybok, G. L. Johnson, and P. A. Pasteris, 2000: High-quality spatial climate data sets for the United States and beyond. Trans. ASAE, 43, 1957-1962, https://doi.org/10.13031/2013.3101.

Dee, D. P., and Coauthors, 2011: The ERA-Interim reanalysis: Configuration and performance of the data assimilation system. Quart. J. Roy. Meteor. Soc., 137, 553-597, https://doi.org/ 10.1002/qj.828.

DeFlorio, M. J., D. E. Waliser, B. Guan, F. M. Ralph, and F. Vitart, 2019: Global evaluation of atmospheric river subseasonal prediction skill. Climate Dyn., 52, 3039-3060, https://doi.org/ 10.1007/s00382-018-4309-x.

Dettinger, M. D., F. M. Ralph, and J. J. Rutz, 2018: Empirical return periods of the most intense vapor transports during historical atmospheric river landfalls on the U.S. West Coast. J. Hydrometeor., 19, 1363-1377, https://doi.org/10.1175/JHMD-17-0247.1.

Dong, L., L. R. Leung, F. Song, and J. Lu, 2018: Roles of SST versus internal atmospheric variability in winter extreme precipitation variability along the U.S. West Coast. J. Climate, 31, 80398058, https://doi.org/10.1175/JCLI-D-18-0062.1.

Flanagan, P. X., J. B. Basara, J. C. Furtado, and X. Xiao, 2018: Primary atmospheric drivers of pluvial years in the United
States Great Plains. J. Hydrometeor., 19, 643-658, https:// doi.org/10.1175/JHM-D-17-0148.1.

Frei, A., K. E. Kunkel, and A. Matonse, 2015: The seasonal nature of extreme hydrological events in the northeastern United States. J. Hydrometeor., 16, 2065-2085, https://doi.org/10.1175/ JHM-D-14-0237.1.

Gershunov, A., T. Shulgina, F. M. Ralph, D. A. Lavers, and J. J. Rutz, 2017: Assessing the climate-scale variability of atmospheric rivers affecting western North America. Geophys. Res. Lett., 44, 7900-7908, https://doi.org/10.1002/2017GL074175.

Gitro, C., M. Evans, and R. Grumm, 2014: Two major heavy rain/ flood events in the mid-Atlantic: June 2006 and September 2011. J. Oper. Meteor., 2, 152-168, https://doi.org/10.15191/ nwajom.2014.0213.

Guan, B., and D. E. Waliser, 2015: Detection of atmospheric rivers: Evaluation and application of an algorithm for global studies. J. Geophys. Res. Atmos., 120, 12 514-12 535, https://doi.org/ 10.1002/2015JD024257.

Haberlie, A. M., and W. S. Ashley, 2019: A radar-based climatology of mesoscale convective systems in the United States. J. Climate, 32, 1591-1606, https://doi.org/10.1175/JCLI-D-18-0559.1.

Hirata, F. E., and A. M. Grimm, 2017: The role of synoptic and intraseasonal anomalies on the life cycle of rainfall extremes over South America: Non-summer conditions. Climate Dyn., 49, 313-326, https://doi.org/10.1007/s00382-016-3344-8.

Jiang, R., T. Y. Gan, J. Xie, and N. Wang, 2014: Spatiotemporal variability of Alberta's seasonal precipitation, their teleconnection with large-scale climate anomalies and sea surface temperature. Int. J. Climatol., 34, 2899-2917, https://doi.org/ 10.1002/JOC.3883.

Jones, C., and L. M. V. Carvalho, 2012: Spatial-intensity variations in extreme precipitation in the contiguous United States and the Madden-Julian oscillation. J. Climate, 25, 4898-4913, https://doi.org/10.1175/JCLI-D-11-00278.1.

, D. E. Waliser, K. M. Lau, and W. Stern, 2004: Global occurrences of extreme precipitation and the Madden-Julian oscillation: Observations and predictability. J. Climate, 17, 4575-4589, https://doi.org/10.1175/3238.1.

Karl, T. R., and R. W. Knight, 1998: Secular trends of precipitation amount, frequency, and intensity in the United States. Bull. Amer. Meteor. Soc., 79, 231-242, https://doi.org/10.1175/15200477(1998)079<0231:STOPAF $>2.0 . \mathrm{CO} ; 2$.

Kenyon, J., and G. C. Hegerl, 2010: Influence of modes of climate variability on global precipitation extremes. J. Climate, 23, 6248-6262, https://doi.org/10.1175/2010JCLI3617.1.

Konrad, C. E., 2001: The most extreme precipitation events over the eastern United States from 1950 to 1996: Considerations of scale. J. Hydrometeor., 2, 309-325, https://doi.org/10.1175/ 1525-7541(2001)002<0309:TMEPEO > 2.0.CO;2.

Kottek, M., J. Grieser, C. Beck, B. Rudolf, and F. Rubel, 2006: World map of the Köppen-Geiger climate classification updated. Meteor. Z., 15, 259-263, https://doi.org/10.1127/09412948/2006/0130.

Kunkel, K. E., S. A. Changnon, and J. R. Angel, 1994: Climatic aspects of the 1993 Upper Mississippi River Basin flood. Bull. Amer. Meteor. Soc., 75, 811-822, https://doi.org/10.1175/15200477(1994)075<0811:CAOTUM > 2.0.CO;2.

Lackmann, G. M., 2013: The south-central U.S. flood of May 2010: Present and future. J. Climate, 26, 4688-4709, https://doi.org/ 10.1175/JCLI-D-12-00392.1.

Lavers, D. A., and G. Villarini, 2013: Atmospheric rivers and flooding over the central United States. J. Climate, 26, 78297836, https://doi.org/10.1175/JCLI-D-13-00212.1. 
Lynch, S. L., and R. S. Schumacher, 2014: Ensemble-based analysis of the May 2010 extreme rainfall in Tennessee and Kentucky. Mon. Wea. Rev., 142, 222-239, https://doi.org/10.1175/MWRD-13-00020.1.

Maddox, R. A., C. F. Chappell, and L. R. Hoxit, 1979: Synoptic and meso- $\alpha$ scale aspects of flash flood events. Bull. Amer. Meteor. Soc., 60, 115-123, https://doi.org/10.1175/1520-0477-60.2.115.

Mahoney, K., and Coauthors, 2016: Understanding the role of atmospheric rivers in heavy precipitation in the southeast United States. Mon. Wea. Rev., 144, 1617-1632, https:// doi.org/10.1175/MWR-D-15-0279.1.

Mallakpour, I., and G. Villarini, 2016: Analysis of changes in the magnitude, frequency, and seasonality of heavy precipitation over the contiguous USA. Theor. Appl. Climatol., 130, 345363, https://doi.org/10.1007/s00704-016-1881-z.

Marciano, C. G., and G. M. Lackmann, 2017: The South Carolina flood of October 2015: Moisture transport analysis and the role of Hurricane Joaquin. J. Hydrometeor., 18, 2973-2990, https://doi.org/10.1175/JHM-D-16-0235.1.

Moore, B. J., K. M. Mahoney, E. M. Sukovich, R. Cifelli, and T. M. Hamill, 2015: Climatology and environmental characteristics of extreme precipitation events in the southeastern United States. Mon. Wea. Rev., 143, 718-741, https://doi.org/10.1175/ MWR-D-14-00065.1.

Mundhenk, B. D., E. A. Barnes, E. D. Maloney, and C. F. Baggett, 2018: Skillful empirical subseasonal prediction of landfalling atmospheric river activity using the Madden-Julian oscillation and quasi-biennial oscillation. npj Climate Atmos. Sci., 1, 20177, https://doi.org/10.1038/S41612-017-0008-2.

National Academies of Sciences, Engineering and Medicine, 2016: Next Generation Earth System Prediction: Strategies for Subseasonal to Seasonal Forecasts. National Academies Press, 350 pp., https://doi.org/10.17226/21873.

National Centers for Environmental Information, 2019: U.S. billion-dollar weather and climate disasters. NOAA, https:// www.ncdc.noaa.gov/billions/.

Newell, R. E., N. E. Newell, Y. Zhu, and C. Scott, 1992: Tropospheric rivers?-A pilot study. Geophys. Res. Lett., 19, 2401-2404, https://doi.org/10.1029/92GL02916.

Oklahoma Mesonet, 2015: Historic May rains eliminate drought. Oklahoma Mesonet, https://www.mesonet.org/index.php/news/ article/historic_may_rains_eliminate_drought.

PRISM Climate Group, 2017: PRISM Climate Data. PRISM Climate Group, accessed 10 October 2017, http://prism. oregonstate.edu.

Reidmiller, D. R., C. W. Avery, D. R. Easterling, K. E. Kunkel, K. L. M. Lewis, T. K. Maycock, and B. C. Stewart, Eds., 2018: Impacts, Risks, and Adaptation in the United States. Vol. II, Fourth National Climate Assessment, U.S. Global Change Research Program, 1515 pp., https://doi.org/10.7930/NCA4.2018.

Rivera, E. R., F. Dominguez, and C. L. Castro, 2014: Atmospheric rivers and cool season extreme precipitation events in the Verde River basin of Arizona. J. Hydrometeor., 15, 813-829, https://doi.org/10.1175/JHM-D-12-0189.1.

Rogers, J. C., 1981: The North Pacific Oscillation. J. Climatol., 1, 39-57, https://doi.org/10.1002/joc.3370010106.

Rutz, J. J., W. J. Steenburgh, and F. M. Ralph, 2015: The inland penetration of atmospheric rivers over western North
America: A Lagrangian analysis. Mon. Wea. Rev., 143, 1924 1944, https://doi.org/10.1175/MWR-D-14-00288.1.

Saharia, M., P. E. Kirstetter, H. Vergara, J. J. Gourley, and Y. Hong, 2017: Characterization of floods in the United States. J. Hydrol., 548, 524-535, https://doi.org/10.1016/j.jhydrol.2017. 03.010.

Schumacher, R. S., and R. H. Johnson, 2006: Characteristics of U.S. extreme rain events during 1999-2003. Wea. Forecasting, 21, 69-85, https://doi.org/10.1175/WAF900.1.

Slater, L. J., G. Villarini, and A. A. Bradley, 2019: Evaluation of the skill of North-American Multi-Model Ensemble (NMME) global climate models in predicting average and extreme precipitation and temperature over the continental USA. Climate Dyn., 53, 7381-7396, https://doi.org/10.1007/s00382016-3286-1.

Thompson, D. W. J., and J. M. Wallace, 2000: Annular modes in the extratropical circulation. Part I: Month-to-month variability. J. Climate, 13, 1000-1016, https://doi.org/10.1175/1520-0442 (2000)013<1000:AMITEC > 2.0.CO;2.

Touma, D., A. M. Michalak, D. L. Swain, and N. S. Diffenbaugh, 2018: Characterizing the spatial scales of extreme daily precipitation in the United States. J. Climate, 31, 8023-8037, https://doi.org/10.1175/JCLI-D-18-0019.1.

Wallace, J. M., and D. S. Gutzler, 1981: Teleconnections in the geopotential height field during the Northern Hemisphere winter. Mon. Wea. Rev., 109, 784-812, https://doi.org/10.1175/ 1520-0493(1981)109<0784:TITGHF>2.0.CO;2.

Wang, H., R. Fu, A. Kumar, and W. Li, 2010: Intensification of summer rainfall variability in the southeastern United States during recent decades. J. Hydrometeor., 11, 1007-1018, https:// doi.org/10.1175/2010JHM1229.1.

Wang, S.-Y. S., W.-R. Huang, H.-H. Hsu, and R. R. Gillies, 2015: Role of the strengthened El Niño teleconnection in the May 2015 floods over the southern Great Plains. Geophys. Res. Lett., 42, 8140-8146, https://doi.org/10.1002/2015GL065211.

Weaver, S. J., S. Baxter, and K. Harnos, 2016: Regional changes in the interannual variability of U.S. warm season precipitation. J. Climate, 29, 5157-5173, https://doi.org/10.1175/JCLI-D-1400803.1.

Wheeler, M. C., and H. H. Hendon, 2004: An all-season real-time multivariate MJO index: Development of an index for monitoring and prediction. Mon. Wea. Rev., 132, 1917-1932, https://doi.org/ 10.1175/1520-0493(2004)132<1917:AARMMI>2.0.CO;2.

Wick, G. A., P. J. Neiman, and F. M. Ralph, 2013: Description and validation of an automated objective technique for identification and characterization of the integrated water vapor signature of atmospheric rivers. IEEE Trans. Geosci. Remote Sens., 51, 2166-2176, https://doi.org/10.1109/TGRS.2012. 2211024.

Zhao, S., Y. Deng, and R. X. Black, 2017: A dynamical and statistical characterization of U.S. extreme precipitation events and their associated large-scale meteorological patterns. J. Climate, 30, 1307-1326, https://doi.org/10.1175/JCLI-D15-0910.1.

Zheng, C., E. Kar-Man Chang, H.-M. Kim, M. Zhang, and W. Wang, 2018: Impacts of the Madden-Julian oscillation on storm-track activity, surface air temperature, and precipitation over North America. J. Climate, 31, 6113-6134, https:// doi.org/10.1175/JCLI-D-17-0534.1. 